\title{
Occupational risk assessment and selected morbidities among cement brick unit workers in a rural area of Bangalore District, India
}

\author{
Sunny $\mathrm{S}^{1}$, Fathima $\mathrm{FN}^{2}$, Joy $\mathrm{J}^{3}$, Passah $\mathrm{BL}^{3}$, Thomas $\mathrm{JC}^{3}$, Agrawal $\mathrm{T}^{2}$ \\ ${ }^{1}$ Post-graduate student, Department of Community Health, St. John's Medical College, Karnataka, India \\ ${ }^{2}$ Associate Professor, Department of Community Health, St. John's Medical College, Karnataka, India \\ ${ }^{3}$ Intern, Department of Community Health, St. John's Medical College, Karnataka, India
}

\section{ABSTRACT}

Introduction: The labor-intensive nature of cement brick manufacturing, its unorganized nature and internal migration, expose the employees to several occupational health hazards. The objective of the study was to assess the occupational risks in cement brick unit settings and to estimate the prevalence of respiratory and musculoskeletal morbidities among the cement brick unit workers in a rural area of Bangalore urban district.

Methods: A cross-sectional study was conducted among cement brick unit workers over two months. A semistructured questionnaire was used to capture sociodemographic details. Multiple observations on the field and the World Health Organization semi-quantitative risk assessment matrix were used to obtain risk scores of the occupational hazards. A structured questionnaire on respiratory symptoms and Minispir Portable Spirometer were used to assess the respiratory morbidities and lung functions. Musculoskeletal morbidities were assessed using the Modified Nordic questionnaire. Proportions were used to describe respiratory and musculoskeletal morbidities. Chi-square test, Fisher's exact test and multivariate logistic regressions were done to identify significant variables. Results: Among 120 subjects, 110 (91.6\%) were men and $85.8 \%$ were migrants. Injury due to falls of heavy objects, back injury, respiratory complaints and slips/falls were found to be high-risk health hazards. The prevalence of respiratory morbidity was $21.7 \%$ and that of musculoskeletal morbidity was $51.7 \%$. Workers receiving a higher salary ( $\geq 1500$ Indian rupees) had higher odds of having respiratory morbidity.

Conclusion: The prevalence of respiratory and musculoskeletal morbidities was high. Introduction of mechanical equipment, decreasing work hours, periodic medical examinations and appropriate use of personal protective equipment will help in risk reduction as per this study.

Key words: Health Hazards, Lung, Musculoskeletal, Risk Assessment, Spirometry.

DOI: https://doi.org/10.3126/ijosh.v12i1.41033

Conflicts of interest: None

Supporting agencies: None

Date of submission: 14.05.2021

Date of acceptance: 04.07.2021

Date of publication: 01.01.2022

\section{Corresponding Author}

Dr. Twinkle Agrawal

Associate professor,

Department of Community Health,

St. John's Medical College,

Bengaluru - 560034,

Karnataka, India

Phone numbers: +919886267362

E-mail address: doctwinkle@gmail.com

ORCID ID: https://orcid.org/0000-0003-4636-3846

\section{INTRODUCTION}

ndia is the second largest producer of bricks in the world, close behind China. ${ }^{1}$ There is a growing demand for bricks in the construction sector in India due to expanding population. Cement bricks are growing in popularity among homeowners. Cement brick unit workers belong to the unorganized working sector, consisting of all unincorporated private enterprises owned by individuals or households engaged in the sale or production of goods and services operated on a proprietary or partnership basis and with less than ten total workers. ${ }^{2}$ These workers do not have employment

\section{(c) (7) \&}

This journal is licensed under a Creative Commons AttributionNon Commercial 4.0 International License. 
benefits or social security. Although there has been a shift out of agriculture, construction has absorbed more workers than other sectors in recent years. Many workers that are employed in the construction industry are mainly migrants belonging to the lower socio-economic status of society. As a result, these individuals belong to the vulnerable population - in terms of lack of work security and health benefits. ${ }^{3}$

Owing to the labor-intensive nature of cement brick manufacturing, constant exposure to cement dust, lack of adequate personal protective equipment, rigorous hand-intensive jobs for a prolonged period, the use of machines, carrying heavy loads during work and poor ergonomics due to the suboptimal physiological postures adopted by these workers for long periods, skin contact with cement resulting in irritation, these workers are exposed to various occupational hazards including occupational lung disorders, physical injuries, skin conditions and musculoskeletal disorders (MSDs). ${ }^{3,4}$

This study was conducted with the objectives to assess the occupational risks in cement brick unit settings and to estimate the prevalence of musculoskeletal and respiratory morbidities among the cement brick unit workers in a rural area of Bangalore urban district.

\section{METHODS}

This was a quantitative cross-sectional study conducted in three subcentre areas (Mugalur, Kuthganahalli and Handenahalli) of Sarjapur PHC area, in Bangalore Urban District of Karnataka, India. The study was conducted from March to April 2018. Brickfield workers were the study population and convenience sampling was used to select the cement brick units.Permission for data collection was sought from the management of each cement brick unit. All workers in the selected brickfields were assessed for eligibility and willingness to participate in the study. Workers with any history of pre-existing respiratory or musculoskeletal disorders before enrolment in the cement brick units were excluded from the study.

After obtaining written informed consent, a semistructured interview schedule was administered to the study participants. The interview schedule was prepared in English and translated to local language (Kannada/Hindi) following the standard translation process, which was used at their workplace.
The WHO risk assessment matrix was used to categorize the occupational hazards that were observed on the field and also reported by the workers. The WHO risk assessment captures the severity of the hazard in the horizontal axis ranging from insignificant to catastrophic with scores 1 to 16 (multiples of 2) and the likelihood of the hazard in the vertical axis ranging from very unlikely to almost certain with scores 1 to 5 . Risk scores were calculated by multiplying severity and likelihood scores. Risk levels were categorized into low risk (score <6), medium risk (7 - 12), high risk (13-32), and very high risk $(>32)$ and color codes were given from green to red. ${ }^{5}$ Repeated visits were made by the researchers to the cement brick units to assess the severity and likelihood of each hazard.

We also administered a standardized Modified Nordic questionnaire to estimate the prevalence and pattern of musculoskeletal disorders as well as a structured questionnaire on respiratory symptoms. ${ }^{6}$ The Modified Nordic questionnaire consisted of structured binary or multiple-choice questions on musculoskeletal symptoms during the last seven days and twelve months. Minispir Portable Spirometer was used to assess the lung function of the workers. Spirometry was carried out using a nose clip and separate mouthpiece for each worker by the researcher who was trained by the pulmonary department. Explanations were given in detail on the procedure and a demonstration was done to the workers. They were encouraged to practice the steps before performing the actual test. Pulmonary Function Test (PFT) parameters including forced expiratory volume in the first second (FEV1), forced vital capacity (FVC) and FEV1/FVC were measured. Individuals with abnormal spirometry readings were considered to have respiratory morbidity.

Data were compiled and entered into Microsoft Excel and analyzed using IBM SPSS (Statistical Package for the Social Sciences) version 16.0 software. Descriptive statistics including mean with standard deviation, median, and percentages were used for socio-demographic details. Proportions were used for explaining the prevalence of respiratory and musculoskeletal morbidities. Bivariate analysis using the Chi-square test or Fisher's Exact test was done to find associations between socio-demographic details and the morbidities identified. Multivariate analysis was done taking into consideration the significant variables identified through bivariate analysis of musculoskeletal and respiratory morbidities and the model was adjusted 
for smoking history and the adjusted odds ratio (AOR) with a $95 \%$ confidence interval was calculated. A $p$-value of $<0.05$ was considered statistically significant.

\section{RESULTS}

A total of 120 workers participated in the study. The mean age of the population was $28.03 \pm 11.38$ years. The majority of them were in the $21-30$ years age group. In this study, $92 \%$ of the study population were males and a majority of them (86\%) were migrants. Most of them had primary school education (44\%), followed by upper primary school education (27\%). Around $22 \%$ of the population were illiterate. The median monthly salary was found to be 4000 Indian rupees (Interquartile range (IQR) 3000;5000). The mean working hours per day were $9.03 \pm 2.05$ hours. Most of them worked for eight hours $(25.8 \%)$ or twelve hours $(23.3 \%)$ on a single day. The majority of them $(81.7 \%)$ worked for a minimum of six days during the week, followed by whole week (10.8\%) and five days of a week (5.8\%).

Our study also looked at the use of personal protective equipment (PPE) among the workers and we found that $88 \%$ of the workers used gloves while working in the cement brick units. The gloves used were not of the recommended standards and other PPE including masks, goggles, or boots were not used by workers.

On health risk assessment we found that fall of heavy objects (Risk score 32), cuts/crushes (32), back injury (24), respiratory morbidities (24), musculoskeletal disorders (20) and slips/falls (16) fell into the highrisk category. Heat exhaustion/dehydration (12), skin problems (12) mental health issues (8), and eye irritation (6) were found to be of medium risk. Vibration injury (4) was found to be of low risk while very high-risk hazards were not found in our study. The prevalence of musculoskeletal disorders was found to be $51.7 \%$. Lower back pain was the major complaint by the employees (51.7\%). Among the $51.7 \%$ who had back pain, $16.1 \%$ were not able to work because of the pain, $25.8 \%$ had seen a doctor for the same and $46.7 \%$ had trouble in the last seven days. Following lower back pain, shoulder pain was the other major complaint given by the employees $(22.5 \%)$ (Table 1 ).

Bivariate analysis showed a significant association between monthly salary and musculoskeletal pain (Table 2).

In our study, the prevalence of respiratory morbidities was found to be $59 \%$ and $21.7 \%$ had a cough in the morning, $11.7 \%$ had breathlessness and $8.3 \%$ had phlegm in the morning. Among the workers, 20.0\% were smokers. The mean age at which smoking was started was found to be $17.04 \pm 6.32$ years and the median number of cigarettes smoked per day was 3.00 (IQR 2,5). On performing pulmonary function tests using the portable spirometer, we found the mean FVC, FEV1 and FEV1/FVC to be $2.65 \pm 0.68 \mathrm{~L}, 2.52 \pm 0.62$ L, $95.56 \pm 7.25$, respectively. On PFT interpretation, $26(21.7 \%)$ had mild, $27(22.5 \%)$ had moderate, 12 $(10.0 \%)$ had moderate to severe and $6(5.0 \%)$ had severe restriction.

Bivariate analysis showed a significant association between female gender, increased monthly salary ( $\geq 5000$ Indian rupees) and abnormal PFT (FEV1). Increased work hours ( $\geq 10$ hours) and increased monthly salary ( $\geq 5000$ Indian rupees) were also found to be significantly associated with respiratory morbidity. On multivariate analysis, we found that employees getting a salary of $\geq 5000$ Indian rupees had almost three times (aOR 2.96; 95\% Cl 1.161 - 7.553) odds of having respiratory morbidity compared to those getting $\leq 3000$ Indian rupees as monthly salary (Table 3 ).

Table 1: Musculoskeletal complaints among the study subjects $(n=120)$

\begin{tabular}{ccccc}
\hline & $\begin{array}{c}\text { Any trouble in last } \\
\mathbf{1 2} \text { months } \mathbf{n}(\mathbf{\%})\end{array}$ & $\begin{array}{c}\text { Not able to work } \mathbf{n} \\
(\mathbf{\%})\end{array}$ & $\begin{array}{c}\text { Seen a doctor for } \\
\text { the same } \mathbf{n}(\%)\end{array}$ & $\begin{array}{c}\text { Any trouble in last } \mathbf{7} \\
\text { days } \mathbf{n}(\%)\end{array}$ \\
\hline Neck & $9(7.5)$ & $1(10)$ & $7(77.7)$ & $8(88.9)$ \\
Shoulders & $27(22.5)$ & $4(14.8)$ & $12(44.4)$ & $17(63.0)$ \\
Upper back & $17(14.2)$ & $1(5.8)$ & $6(35.3)$ & $8(53.0)$ \\
Elbows & $11(9.2)$ & $1(9.09)$ & $6(72.7)$ & $9(81.8)$ \\
Wrists/Hand & $13(10.8)$ & $2(15.3)$ & $16(25.8)$ & $9(69.2)$ \\
Lower back & $62(51.7)$ & $10(16.1)$ & $8(80.0)$ & $9(46.7)$ \\
Hips/Thighs & $10(8.3)$ & $1(10.0)$ & $6(35.3)$ & $11(64.7)$ \\
Knees & $17(14.2)$ & $1(5.9)$ & $3(75)$ & $4(100.0)$ \\
\hline Ankles/Feet & $4(3.3)$ & $3(75)$ & & \\
\hline
\end{tabular}


Table 2: Association between sociodemographic details and musculoskeletal morbidity among the study subjects $(n=120)$

\begin{tabular}{ccccc}
\hline Variables & Categories & $\begin{array}{c}\text { Musculoskeletal } \\
\text { morbidity absent }\end{array}$ & $\begin{array}{c}\text { Musculoskeletal } \\
\text { morbidity present }\end{array}$ & p-value \\
\hline Gender & Males & $54(49.1)$ & $56(50.9 \%)$ & $0.745^{*}$ \\
Monthly salary & $\leq 3000$ & $4(40.0)$ & $6(60.0)$ & $31(72.1)$ \\
(Indian Rupees) & $3001-4999$ & $12(27.9)$ & $21(56.8)$ & $<0.001 \dagger$ \\
& $\geq 5000$ & $16(43.2)$ & $10(25.0)$ & \\
Work hours & $<7$ & $30(75.0)$ & $11(68.8)$ & 0.099 \\
\hline
\end{tabular}

* Fisher's Exact test; $†$ Statistically significant at $\alpha=5 \%$

Table 3: Multivariate logistic regression: factors associated with respiratory morbidity $(n=120)$

\begin{tabular}{|c|c|c|c|c|c|}
\hline \multirow{2}{*}{ Variables } & \multirow{2}{*}{ Categories } & \multirow{2}{*}{ Adjusted Odds ratio } & \multicolumn{2}{|c|}{$95 \% \mathrm{Cl}$ for Odds Ratio } & \multirow{2}{*}{ p-value } \\
\hline & & & Lower Limit & Upper Limit & \\
\hline \multirow{3}{*}{$\begin{array}{l}\text { Monthly salary } \\
\text { (Indian rupees) }\end{array}$} & $\leq 3000$ & & & & 0.058 \\
\hline & $3001-4999$ & 1.33 & 0.494 & 3.600 & 0.571 \\
\hline & $\geq 5000$ & 2.96 & 1.161 & 7.553 & $0.023^{*}$ \\
\hline \multirow{2}{*}{ Gender } & Females & 4.113 & 0.959 & 17.632 & 0.057 \\
\hline & Males & & & & 0.583 \\
\hline
\end{tabular}

*Statistically significant at $\alpha=5 \%$

\section{DISCUSSION}

The main occupational health risks identified in our study were fall of heavy objects, cuts/ crushes, back injury, respiratory morbidities, musculoskeletal disorders and slips/falls. In our study, the prevalence of musculoskeletal and respiratory morbidities was $51.7 \%$ and $59.0 \%$ respectively. The findings of our study will help in limiting the hazards by identifying risks involved in the work of cement unit workers and thereby reducing morbidities among the unorganized sectors.In our study, the mean hours of work were $9.03 \pm 2.05$ hours, which was similar to other studies. ${ }^{3,7}$ The cement brick unit employees work for more hours resulting in increased exposure to health hazards.

The majority of the studies done previously on brick workers were among brick kiln workers and our study was done among the cement brick unit workers. A study in Bangladesh on the health hazards of brickfield workers found that lack of pure drinking water $(98.01 \%)$, extremely hot environment (95.52\%) and very hard work $(93.78 \%)$ as the major hazards. Among the respondents, $89.30 \%$ and $31.84 \%$ reported that flying dust and brick falling on workers as the other major problems and limitations. ${ }^{8}$ Similarly, Srivastava
AK, identified silicosis $(6.52 \%)$, chronic bronchitis $(4.66 \%)$, callosities $(8.17 \%)$, eye irritation (3.50\%), and pain in limbs or back $(8.56 \%)$ as the major risks among brick kiln workers. ${ }^{9}$ In our study falling of heavy objects, cuts/crushes and back injury were identified as the high-risk hazards. The difference might be due to the fact that cement bricks are heavier and during their production, the workers are exposed to more dust and cement particles. While in the case of clay bricks the workers are exposed to the smoke and the high temperature in the kilns.

In our study, the prevalence of musculoskeletal morbidity was found to be $51.7 \%$ and the most common affected site was the lower back. A study by Inbaraj, et al., found the prevalence of musculoskeletal disorders among brick kiln workers to be $87 \%$ and the most affected regions were lower back (59\%), knee (44.8\%), shoulder $(23.5 \%)$, ankle $(22.9 \%)$, elbow and hips $(20.6 \%)$, wrist $(13.9 \%)$, neck $(11.3 \%)$ and upper back $(8.7 \%) .{ }^{4}$ According to Das $B$ and Mukhopadhyay $P$ majority of the brick kiln workers suffered from discomfort mainly in the lower back. ${ }^{3,10}$ The study conducted by Qutubuddin SM, found that the postures adopted by the brick kiln workers were vulnerable to musculoskeletal disorders. ${ }^{11}$ In the majority of the studies including the current study, the most affected 
area was the lower back, owing to the unergonomic postures and heavy lifting these workers have to do daily. The lower prevalence of musculoskeletal morbidity in our study compared to other studies can be attributed to the younger age groups of our study population.

The prevalence of respiratory morbidity in our study was found to be $59 \%$. A study conducted by Thomas $\mathrm{BE}$ identified respiratory symptoms among the $10.4 \%$ males and $8.3 \%$ of females working in a brick kiln in South India. In the study conducted by Das B, the prevalence of various respiratory symptoms was dyspnoea $(46.8 \%)$, phlegm $(39.2 \%)$, chest tightness (27.6\%), sneezing (28.8\%) and wheezing (14.4\%) while, Tandon, et al., found the prevalence of frequent coughing $(67.2 \%)$, shortness of breath $(60 \%)$, irritation in the respiratory tract $(83.6 \%)$, chronic phlegm $(70 \%)$ and chest tightness (54.5\%) to be high among the workers in brick kilns. ${ }^{12}$ A study conducted by Shaikh, et al., identified the prevalence of chronic cough among brick kiln workers in Pakistan to be $22.4 \%$ and chronic phlegm to be $21.2 \% .^{7}$ In the study conducted by Sanjel, et al., in Nepal the prevalence of chronic cough, phlegm and bronchitis were $14.3 \%, 16.6 \%$ and $19.0 \%$ respectively. ${ }^{13}$ The high prevalence of respiratory symptoms in our study can be attributed to the increased dust generated from both cement and sand used in the manufacturing of cement bricks.

The high prevalence of respiratory symptoms was evident in the $\mathrm{PFT}$ readings in our study. In various studies, the FVC, FEV1 and FEV1/FVC values ranged between 2.01 to $3.72 \mathrm{~L}, 1.65$ to $2.95 \mathrm{~L}$ and 76.33 to $83.69 \%$ respectively. $3,14,12,15$ The PFT readings in our study fell in these ranges showing the effect of air pollution in the respiratory tract due to lack of PPE.

Our study identified that respiratory morbidity was associated with an increased monthly salary of more

\section{REFERENCES}

1. Wanjule PB, Chadanshiv SB, Aswale S. Brick Making in India - History. International Journal Of Marketing Financial Services \& Management Research. 2015;4(11):11-6.

2. Sengupta AK. Report on conditions of work and promotion of livelihoods in the unorganized sector. New Delhi, Academic Foundation. 2008;1.

3. Das B. Assessment of occupational health problems and physiological stress among the brick field than 5000 Indian rupees $(\mathrm{aOR} 2.96 ; 95 \% \mathrm{Cl} 1.16$ 7.55). Thomas, et al., identified that the respiratory symptoms were associated with illiteracy (aOR 1.9; $95 \% \mathrm{Cl} 1.4-2.5)$, duration of stay for more than six months in the current chamber (aOR 1.96, 95\% Cl 1.3 - 2.9), high risk of alcohol intake (aOR 2.9; 95\% $\mathrm{Cl} 1.6$ - 5.2) and heavy smoking (aOR 1.6; 95\% Cl 1.2 - 2.2). ${ }^{16}$ The deterioration of the lung functions among the brick kiln workers was associated with the duration of exposure. ${ }^{12}$ In the Nepalese study, the age of participants and duration of work were significant predictors for chronic cough ( $p<0.001$ each). Duration of work was also significantly associated with the development of chronic phlegm. ${ }^{13}$ In our study income acted as a surrogate for the working hours since the workers were paid according to the number of hours they worked in the cement brick units.

\section{CONCLUSION}

In this study, the main health risks identified were injuries due to falling of heavy objects, back injury, cuts/crushes, exposure to cement causing respiratory symptoms and musculoskeletal disorders. The prevalence of respiratory and musculoskeletal disorders was found to be high. The duration of exposure plays a significant role in the development of respiratory morbidities especially in the absence of PPE. Provision and use of personal protective equipment along with better ergonomic postures and safe machinery can reduce the health risks among the workers. Pre-placement and periodic medical examinations can keep a check on the occurrence of other morbidities including respiratory problems. Limitations of the study include the sampling technique used and the limited number of participants in the study. Further studies with better sampling techniques, more study participants and different study designs can provide extra data and thereby strengthen the findings of the study. workers of West Bengal, India. Int J Occup Med Environ Health. 2014; 27(3): 413-25.

4. Inbaraj LR, Haebar OJ, Saj F, Dawson S, Paul P, Paul Prabhakar AK, et al. Prevalence of musculoskeletal disorders among brick kiln workers in rural Southern India. Indian J Occup Environ Med. 2013;17(2): 715.

5. Dujim NJ. Recommendations on the use and design of risk matrices. Safety Science. 2015; 76: 2131.6. Kuorinka I, Jonsson B, Kilbom A, Vinterberg $\mathrm{H}$, Biering-Sorenen $\mathrm{F}$, Andersson G, 
et al. Standardised Nordic questionnaires for the analysis of musculoskeletal symptoms. Appl Ergon. 1987;18(3):233-7.

7. Shaikh S, Nafees AA, Khetpal V, Jamali AA, Arain AM, Yousuf A. Respiratory symptoms and illnesses among brick kiln workers: a cross sectional study from rural districts of Pakistan. BMC Public Health. 2012;12:999.

8. Das S, Hasan MSQ, Akhter R, Huque S, Khandaker $\mathrm{S}$, Gorapi MZH, et al. Socioeconomic conditions and health hazards of brick field workers: A case study of Mymensingh brick industrial area of Bangladesh. $J$ Public Heal Epidemiol. 2017;9:198-205.

9. Srivastava AK, Rastogi SK, Mathur N, Bihari V. Health risk assessment of brick kiln workers. Indian $\mathrm{J}$ Occup Environ Med. 2002;6:150-5.

10. Mukhopadhyay P. Risk factors in manual brick manufacturing in India. Ergonomics Society of Australia. 2008;22:16-25.

11. Qutubuddin SM, Hebbal SS, Kuma ACS. Ergonomic Evaluation of Tasks Performed by Workers in Manual Brick Kilns in Karnataka, India. Global Journal of Researches in Engineering Industrial Engineering. 2013;13: 34-42.
12. Tandon S, Gupta S, Singh S, Kumar A. Respiratory abnormalities among occupationally exposed, nonsmoking brick kiln workers from Punjab, India. Int J Occup Environ Med.2017;8:166-73.

13. Sanjel S, Khanal SN, Thygerson SM, Carter WS, Johnston JD, Joshi SK. Respiratory symptoms and illnesses related to the concentration of airborne particulate matter among brick kiln workers in Kathmandu valley, Nepal. Ann Occup Environ Med. 2017 Mar 27;29:1-12.

14. Das B. Assessment of respiratory symptoms and lung function values among the brick field workers of West Bengal, India. Archives of Environmental and Occupational Health. 2016;71:222-30.

15. Liou SH, Chen YP, Shih WY, Lee CC. Pneumoconiosis and pulmonary function defects in silica-exposed fire brick workers. Archives of Environmental Health. 1996; 51: 227-33.

16. Thomas BE, Charles N, Watson B, et al. Thomas BE, Charles N, Watson B, Chandrasekaran V, Senthil Kumar R, Dhanalakshmi A, et al. Prevalence of chest symptoms amongst brick kiln migrant workers and care seeking behaviour: a study from South India. J Public Health (Oxf). 2015 Dec;37(4):590-6. doi: 10.1093/pubmed/fdu104. Epub 2014 Dec 23. PMID: 25538142. 